\title{
1. Reinventing performance management in the public sector
}

\author{
Jane Gunn, Kristy Zwickert and Kathy Hilyard
}

\section{INTRODUCTION}

It is increasingly evident that performance management practices prevalent in the public sector are underpinned by assumptions that do not serve a contemporary public service. Since performance management was introduced into the public sector, the requirements on public servants have changed markedly and continue to change rapidly. The need for greater agility, innovation and new thinking about service delivery and the achievement of policy outcomes for Australia and its citizens is clear and no longer contentious. Fundamentally, this is an evolving definition of high performance that arguably sits uncomfortably beside requirements for transparency and adherence to due process in a highly scrutinised (and rightly so) context. We argue that performance management can play an important role in supporting public servants and leaders, in particular to navigate these inherent tensions in defining what 'good' looks like as they embrace the shift required and re-imagine a new form of public sector performance. Clearly there are structural aspects to the changes needed to embed new ways of working in the Australian Public Service (APS). We argue that the current performance management frameworks play a role in holding the APS back with tools and assumptions that are no longer fit for purpose and were developed for another time. We propose a new purpose, principles and practical strategies for evolving to a new more contemporary and fit-for-now approach.

Our intent is this chapter contributes to the ongoing academic and practitioner debate regarding high performance public service in a complex and evolving context. It is our hope that these ideas provide a framework against which public sector agencies might compare and evolve their current practices.

\section{THE CHANGING NATURE OF PUBLIC SERVICE}

Numerous reviews have called for a shift in the way that public services adapt in a complex, volatile and unpredictable world. A recent example is the 'Independent Review of the Australian Public Service' (APS), commonly referred to as the Thodey Review (Department of the Prime Minister and Cabinet 2019). The Thodey Review called out the 'rapidly changing world' in which the APS finds itself. It identified technology, declining trust and demographic shifts as three key factors impacting on the nature of public service work. Similarly, the New Zealand government identified that 'the Public Service now operates in a fast changing and unpredictable world where major social, demographic and technology changes are reshaping the world as we know it' (State Services Commission 2019, p. 7). And of course, as we write we are in the midst of a global pandemic that has profoundly impacted both our social and economic stability as a society, creating once in a generation challenges for governments and 


\section{Handbook on performance management in the public sector}

public services at all levels of the federation. It is an unpredictable and disruptive context for today's public services to navigate.

This shift in the context for the contemporary public service demands a change in the way that public servants, and the public service as a whole, work. For leaders, this means 'dropping the model of success that got them this far and accepting that it is not going to work to take that model forward' (Yon Ying-I 2019). Notions of leadership are being reconceptualised and work itself is being reshaped. Estimates indicate that 40 percent of the work public sector employees undertake now could be automated (Department of the Prime Minister and Cabinet 2019) and traditional notions of where work is undertaken are being shaken and brought into sharp focus.

The Thodey Review calls for a public service that 'instinctively pulls together to tackle complex challenges, bringing all of its expertise, perspectives and resources to bear' (Department of the Prime Minister and Cabinet 2019, p. 16). This means having systems, structures and ways of working that empower, not encumber, the flexibility and collaboration essential to advancing Australia's long term interests. 'This is why we see great potential to apply dynamic ways of working and different structures across the service, regardless of department or agency. The objective is to make collaboration the norm' (Thodey 2019).

This theme of cultivating new ways of working to respond to increasing complexity is common across jurisdictions. For example:

- The New South Wales (NSW) Public Service has identified the need to drive uptake of new ways of working, including flexible arrangements, digital, agile, and co-design methodologies to ensure effective and efficient outcomes. There is also an emphasis on the development of transformation and change capabilities to enable the whole of service to adapt more quickly, reduce the costs of change and realise benefits faster (NSW Public Service Commission 2019).

- In a recent review of the State Sector Act, the New Zealand government identified that while decentralisation and agency autonomy were undertaken in the 1980s and 1990s for very good reasons, this is no longer the way that the public service needs to operate in the face of 'cross-cutting problems'. The review identified the need for public servants to work together, across agencies with a common purpose to deliver outcomes, rather than identifying with and working in silos. The Impact Statement: State Sector Act Reform calls for enhancing collaboration whereby 'the expectations of public servants need to be reset to work as a unified public service, and to work across boundaries to deliver better outcomes and services for people' (State Services Commission 2019, p. 11). It argues that this will, in turn, lead to a greater ability to 'effectively join up around citizens', 'generate alignment and interoperability' and 'establish behavioural and cultural foundations for a unified Public Service' (p. 12).

- Similarly in the UK, a call for greater collaboration to achieve so called 'joined up' outcomes, greater focus on the citizen as customers, greater use of technology and innovation to modernise services, with a particular focus on digital delivery. This will require innovation and working together to a greater extent than is currently evidenced (Manzoni 2018).

Of course, public service reform in response to a changing environment is not new. The field of public administration has also experienced progressive reform for more than a century (Denhardt and Denhardt 2000; Institute for Government 2019). Denhardt and Denhardt (2015) provide a useful way to consider the reform that we are seeing in each of the jurisdictions 
explored above. They describe an evolution from 'public administration' that focused on centralised bureaucratic processes and hierarchical controls that limited citizen involvement, to 'public management' involving alternative service delivery mechanisms based on public-choice assumptions. They argued as long ago as the year 2000 that public sectors are moving towards a new reform program defined as a shift from 'public management' towards 'new public service' shifting the role of public services to that of facilitating discourse among disparate stakeholders and citizens to navigate and articulate shared interests, using measures of trust to determine success and co-designing solutions whilst advising government from a base of deep insights regarding competing perspectives. This way of conceiving the changing role and function of public service is also reflected in the concept of changing modes of production in society (Maccoby 2007, 2016). Maccoby brings to our attention the relationship between the shift in the dominant mode of production (from industrial to knowledge based) driving new forms or organisation from the traditional 'bureaucratic' to 'interactive' models (Maccoby 2007, 2016). Maccoby goes on to point out the inevitable shifts required for leadership, working arrangements, expectations of work, and social structures in the workplace.

These shifts in the nature of work are not only specific to public servants, but also reflect broader shifts in the nature of work being felt the world over. The World Economic Forum (2018) forecast that, by 2022, the core skills required to perform most roles will, on average, change by 42 percent. Increasingly, a career for life is perceived to be an artefact of the former working world. The mindset of 'learn, do, retire' no longer provides a future-proofed approach (World Economic Forum 2019). Further, technological advancement and automation will also require new ways of working to manage digital labour and a hybrid workforce. There are a range of emerging technologies at the forefront of the fourth industrial revolution including the cloud, the Internet of Things, Big Data, advanced robotics, artificial intelligence, autonomous vehicles, 3D printing, machine-to-machine technology, renewable energy and next generation genomics. These technologies provide significant benefits and capability development opportunities, but are expected to change the way public services operate by challenging the scope of current occupations and tasks and transforming the way governments deliver services (KPMG 2019). Table 1.1 provides a summary of the key shifts as explored above.

In summary, the response to the challenges of greater complexity, increased citizen focus and demographic, societal and technological change requires fundamentally different ways of working, thereby redefining what constitutes 'high performance'. This is a shift from an emphasis on individual, hierarchically ordered and structured working, undertaken within fixed teams, to collaborative, innovative, cross-team and cross-agency working with a focus on outcomes. The complex and often competing interests of multiple stakeholders challenges the notion that the 'boss' has all the answers, and can define performance outcomes is absurd at best in this changing context.

This change would require a new mindset and skill set from a focus on setting a plan with your boss for the year ahead and then working on the priorities of the moment. Public servants will require the capacity and the mindset to collaborate, undertake on the spot problem solving, take greater risks, adapt to and instigate change all the time, give and receive feedback in the moment. It will require public servants to look up and out and focus on working beyond traditional silos to deliver shared outcomes. In this context, increased value will be placed on cognitive flexibility, learning, creativity, and complex problem solving (World Economic Forum 2016). 
Table 1.1 Summary of key shifts in the nature of public service work

\begin{tabular}{ll}
\hline From & To \\
\hline Centralised bureaucratic processes & Citizen oriented, customer focused, co-design \\
Task oriented & Outcome oriented \\
Hierarchical control & Innovation, rapid problem solving, risk taking \\
Stable, manage change & Constantly evolving, always changing \\
Intra agency focus, silos & Cross agency working to tackle 'cross-cutting' challenges \\
Analogue & Digital \\
Career for life & Many careers, short stints, project based work \\
Human worker centred & Hybrid human digital workforces \\
\hline
\end{tabular}

It is somewhat ironic that, despite a clear and largely uncontested recognition that the public service and public servants need to work in fundamentally different ways, the prevailing approach to performance management, by design, has not yet fully adapted to serve as a vehicle for cultivating these new ways of working. There are some moves to embed new capability frameworks to include agility and adaptability to foster joined up, agile, learning-centred and adaptive behaviours (some Agencies and Departments have developed these frameworks and are encouraging managers and employees alike to work together to develop the new abilities and practices). However there are challenges with implementation, the work of changing practices and behaviours does not stop at the articulation of said behaviours and further investment is required to bring the espoused practices to life in reality. Further, we contend that, a fundamental reset of the approach to performance management will provide one key mechanism to shift the mindsets and practices of public servants and their leaders. A revised approach would start with the underlying assumption of enabling high performance in a complex and changing context. The challenge is to reinvent 'performance management' so that it truly supports the new mindsets and ways of working that the public service needs.

Before we unpack the irony and the opportunity in more detail, we first consider the evidence as to whether performance management approaches have ever actually worked.

\section{DO PERFORMANCE MANAGEMENT SYSTEMS ENABLE HIGH PERFORMANCE?}

Even without considering the relevance of current approaches to performance management given the significant changes in the nature of public service work, it is widely argued that there have always been challenges with performance management systems. Despite the lack of clear evidence, given that studies to determine effectiveness are beset by methodological challenges and are largely of an anecdotal or of a case study nature (see for example Kourtit and de Waal 2008), there is significant doubt that performance management has ever been an effective mechanism for generating high performance.

The introduction of the management of the performance of individuals in public sector organisations, variously called performance appraisal, performance evaluation, or performance development, is credited to have been a result of the new public management movement (mentioned earlier) and its drive for efficiency, transparency and accountability for performance (Fatile 2014). Management by objectives, also called management by results, introduced by Peter Drucker (1954) was also an important theory influencing the implemen- 
tation of performance management techniques. The resource based view (RBV) provided a theoretical underpinning for the notion of performance management by arguing that the skills and resources within an organisation can act as the starting point for competitive advantage (Wernerfelt 1984). Following this logic, the performance of an organisation's internal resources, and particularly people for most organisations where people are the key resources, becomes critically important.

In the military context, performance management techniques were used during World War 1 by the United States to flag and dismiss poor performers and in World War 2 to identify soldiers with the potential to become officers. In subsequent decades, private sector organisations have almost universally used performance management approaches to attempt to motivate and engage employees towards high performance and to manage poor performance (e.g., Goler, Gale and Grant 2016).

Under the influence of these theories and frameworks, performance management systems in the public service were designed with the intent to align employees' efforts to overall agency objectives and to a lesser degree to develop skills and capabilities for the job at hand. For example, 'An effective performance management system is a valuable process which provides employees with greater role clarity by aligning individual performance with key organisational goals and strategic objectives to facilitate ongoing employee, agency and public sector improvement' (Public Sector Commission 2013, p. 6).

Within the Federal Government, recent guidance indicates that the purpose of performance management is ensuring that 'everyone knows how their own performance contributes to the agency achieving its outcomes' (APSC 2019b). In local government, performance management systems have been described as enabling 'organisations to plan, measure and control their performance, so that decisions, resources and activities can be better aligned with strategies to achieve desired results (Baird, Schoch and Chen 2012).

So a key goal in current performance management frameworks and tools is to align the effort of employees to the strategic goals and outcomes an Agency is seeking to deliver.

Another vexed issue in the public sector is the link between performance and rewards for individuals. A number of studies have examined the value of linking employee performance to reward, with mixed results. Baird, Schoch and Chen (2012) reinforced Lawler's (2003) conclusion that staff are more likely to work towards the achievement of organisational objectives if they see a linkage of performance to rewards. However, whilst financial rewards may be successful in generating increased productivity in the short run, the impact on employees' behaviours, and motivation, has been shown to be negative in most research (Metawie and Gilman 2005). Linking rewards to performance is a narrow option for responding to the diverse motivations and drivers of individual performance. As a result of ongoing poor results from performance management processes there is less and less explicit linking of performance ratings to financial rewards in the APS, with very few examples, if any, now in place. Furthermore, behavioural economics research has recently identified a range of other factors that contribute to high performance, such as perceptions of fairness, a personal sense of achievement, friendship and mission (Singler 2018).

Beyond the link to pay, other common criticisms of public sector performance management systems include that they end up being a compliance activity driven by the human resources function, they are retrospective and focused on past actions, they are dependent on the skills of managers in giving feedback which is rarely, if ever, provided in real-time, and goals listed are 
quickly outdated (Neely 1998). Additionally, the term 'performance management' has become associated with the management of underperformance (APSC 2019b).

The latest APS employee census reinforces that the effectiveness of performance management remains problematic. In 2019, Australian Public Sector employees' views on performance management either remained similar or were more negative than previous years (APSC 2019a). Notably, less than half of respondents (48 percent) agreed or strongly agreed that their overall experience of performance management was useful for their development with the remainder either neutral or negative. The other relevant result was that despite the focus on underperformance, only 20 percent of respondents agreed or strongly agreed with the statement 'underperformance is managed effectively' (APSC 2019a).

In 2015, performance management featured in the APSC's Human Capital Matters, a compilation of articles designed for leaders and practitioners in the APS. The editors considered five articles, a mix of private sector practitioner experiences and Australian National Audit Office (ANAO) reports. It was noted that performance management systems do not clearly make a difference to performance outcomes, there are many unintended consequences, and concerns about performance management systems are deeply entrenched and perpetual in nature. The editors summarised their key concerns as:

- The emphasis on process at the expense of discussion and task orientation at the expense of innovation.

- That the approach reinforces concentration of control at the apex, and escalates decision-making up the hierarchy.

- That managers do not prioritise performance management conversations.

- The inability of some managers to objectively assess performance and provide feedback effectively.

Other concerning observations include the lack of clarity about what constitutes high performance and the inherent subjectivity and angst caused by discrepant views of the standards of performance required to obtain a particular performance rating (Blackman et al. 2013). The Independent Review of the Public Service (Department of the Prime Minister and Cabinet 2019) also commented on the inadequacy of current performance management approaches, stating that 'it has been consistently observed that the APS does not do performance management well'.

In light of these weaknesses and evidence that they simply do not deliver what is hoped for, one option is to better implement the current approach to performance management. If it is a problem of implementation, then surely we just need to improve our implementation. While we agree that this might make some degree of difference, we argue instead that the current systems, processes and principles for performance need to be completely transformed. Fixing the current system will not address the reality that the new context calls for an approach better suited to the complex conditions in which the public sector finds itself.

\section{PERFORMANCE MANAGEMENT NEEDS TO CHANGE FOR THIS NEW CONTEXT}

We believe public sector organisations must challenge the very assumptions underpinning the current approach and adopt a different methodology for facilitating high performance. We 
propose that while the systems to date may have been somewhat effective in driving performance in the past (and as we have discussed the evidence here is far from clear), they are ineffective, by design, in developing the behaviours need to create joined up, agile and adaptable public servants. Furthermore, done differently, we believe that performance management can play a central role in bringing about a shift in the culture of the public service and the way that public servants work, that is required.

\section{WHAT SHOULD WE DO INSTEAD?}

We propose a new approach which delivers, through both the way the system works as well as the capabilities and ways of working it is focused on delivering, a shift towards public servants:

- navigating complexity and political contexts to deliver outcomes thinking,

- working better across boundaries,

- engaging more actively in defining and understanding stakeholder interests,

- proactively working to build trust internally and externally,

- deeply understanding the network of perspectives on a particular policy or service delivery challenge,

- collaborating across Agencies, jurisdictions and directly with stakeholders, and

- investing in developing new capability to learn so they can adapt and change.

We also have a nagging thought that the term 'performance management' should be abandoned as dated and insufficient to define the new approach needed. We are also of the view that the process must be removed from the remit of human resources functions and be integrated into business strategy practices. Table 1.2 summarises our perspective, compares it with the common approaches currently in play and expands on the practical design features that deliver on the new assumptions.

As shown in the table and expanded below, we propose that four fundamental features require focused attention to drive and sustain high performance in a complex public sector context:

- First, facilitated interactive dialogues to define outcomes across traditional boundaries, identify interdependencies and agree priorities and responsibilities. Underpinned by curiosity, joined-up and citizen-centric processes and mindsets, a by-product could be higher levels of engagement in that individuals and teams find meaning and purpose in their work, effort is aligned to organisational/service-wide purpose and interdependence is established and accountabilities agreed.

- Second, address individual's motivation to excel through continuous learning and strengths-based engagement to deliver on purpose, roles and responsibilities.

- Third, supporting leaders to reconceptualise their role in leading for high performance, and

- Finally, changing the role that human resources functions play in administering performance frameworks and embedding the performance process in the business strategy activities in recognition of the increasing importance of the link between capability, adaptability and outcomes. 


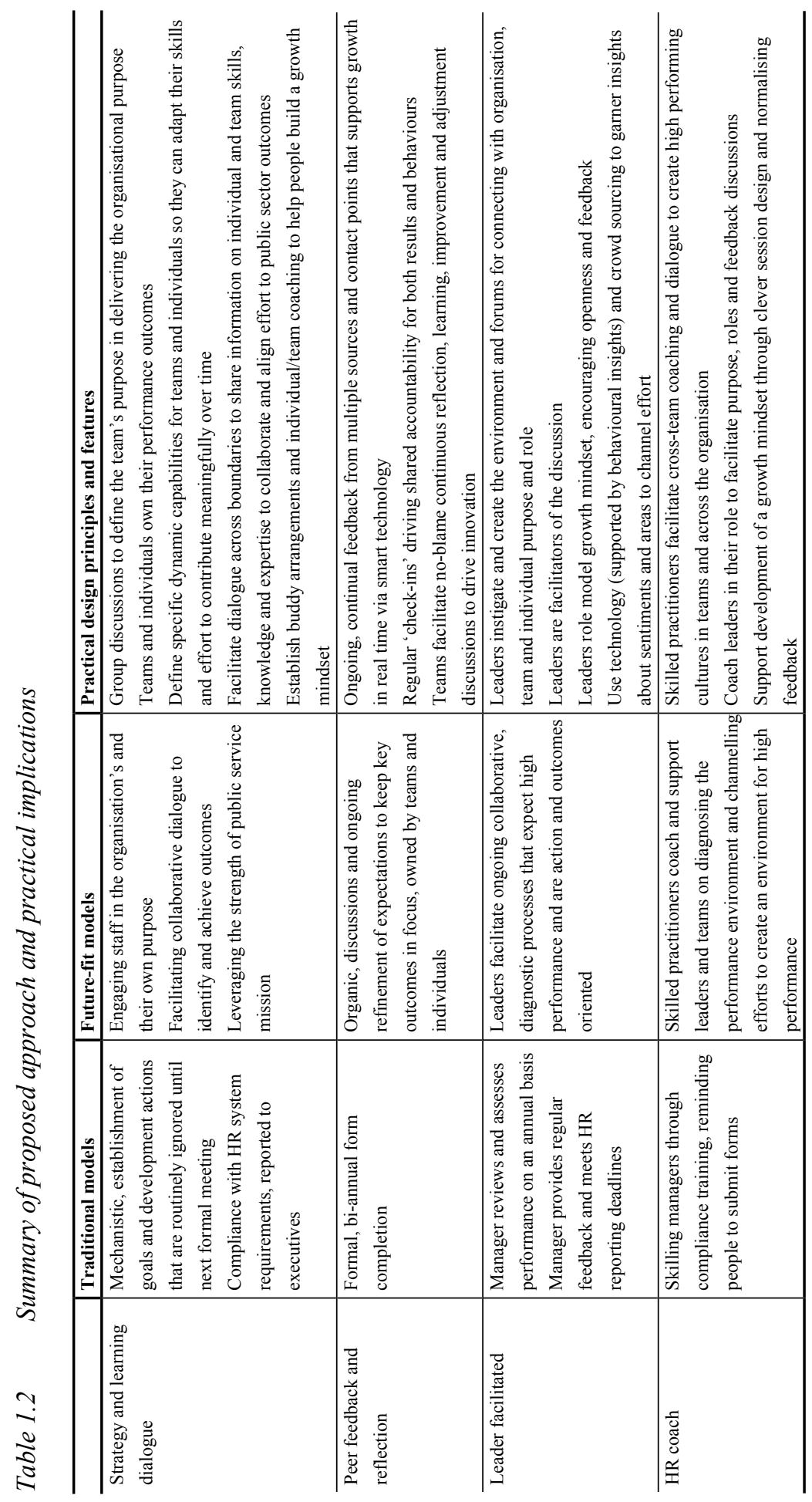




\section{FACILITATE INTERACTIVE DIALOGUE AND COLLABORATION ACROSS BOUNDARIES TO DEFINE PURPOSE AND ALIGN OUTCOMES}

First, we propose that organisations adapt their existing business or strategic planning activities to support the organisation, teams and individuals to identify their purpose and role in achieving outcomes in the context of the broader system in which they are operating. The aim being to establish vehicles for a more strategic boundary-spanning discussion, rather than the traditional task-based approach which is inadequate when the challenges facing government organisations are so dynamic, evolving and complex that no single individual or team can adequately address them (Bommert 2010). As Blackman et al. (2015) note 'the majority of the focus in the performance management literature is on the individual with organisational performance as a secondary concern' (p. 85). Like these authors, and the stated intent of many public sector performance management approaches, we contend that individual performance must be seen in the context of the team or group, the organisation and the system. Interestingly, this is consistent with the ambition of the UK government which has redefined the notion of 'high-performance working' as an 'approach to managing organisations that aims to stimulate more effective employee involvement and commitment to achieve high levels of performance' (UK Government 2009, p. 4).

Practically, this might be structured as facilitated group discussions to define the team's purpose in delivering the organisational purpose. To maximise the opportunity for individuals to see their part in the broader system, it might be useful for this to be a nested (as opposed to cascading) set of discussions, starting with agency heads who have shared policy or citizen outcomes, including agency leadership teams identifying their purpose and roles in achieving the outcomes, and so on to branch and even directorate level with feedback loops to avoid relying solely on a top down approach. This will maximise the opportunity for systems-thinking, collaboration, and the collective intelligence of networks which are tools of vital centrality when it comes to achieving high performance. Public sector performance frameworks and processes now need to support organisations to engage with rich interconnectivity to enable adaptive, rather than ordered, responses to sustain performance in complexity (Uhl-Bien and Arena 2017).

In order to achieve results across boundaries, leaders need to provide a vision and commitment that links and motivates individuals to fundamentally redefine performance outcomes, step beyond their silos, relax old assumptions, and search for creative frame-breaking solutions (Gray 2008). Research shows that collaborative efforts involving public, private, academic, industry and community partnerships who possess the necessary motivation, ideas, skills and resources to craft new public solutions, seem to outperform previous practices and meet unfulfilled demands (Torfing 2019). This shows that determining and holding individuals to account for narrow, short-term tasks is now insufficient in this dynamic environment. New strategies are required for bringing people together to shape, define and achieve outcomes.

Whilst there are compelling arguments for collaborative practices to achieve outcomes in the public sector, implementation, execution and outcomes are not yet widespread. 'Collaborative inertia' describes the (too regular) phenomena where collaborative efforts result in frustration, slow progress and disappointing outputs. Factors causing collaborative inertia include lack of common aims, power struggles, trust issues, fluctuating membership structures and leadership failures (Huxham and Vangen 2013). In addition to collaborative inertia, cultural norms 
and performance incentives often reinforce individualistic achievements over group-based outcomes and hierarchical structures encourage positional power rather than shared power arrangements.

A critical element of this approach is creating the conditions by which teams and individuals own their performance outcomes. This is reflective of the changes made by the UK government who have questioned traditional forms of strategy development, advocating for smart collaboration systems, fostering intergenerational solidarity, and positioning self-management and self-responsibility for outcomes as a key driver of future organisational performance (UK Government 2009).

Therefore, the method by which the discussions are conducted becomes key. It is imperative that this is an empowered discussion whereby individuals and groups take the opportunity to connect with the service-wide, organisational, branch purpose and make connections to their personal contribution, purpose and strengths. So, the business planning discussion also becomes an individual consideration of purpose and role, rather than goals being set individually and approved by managers. We will explore this further in relation to the role of the leaders and human resources.

Clarity of purpose has many advantages and supports employees to adapt and change as the context changes. This changes the dialogue from 'can I tick the box?' to 'is what I'm doing every day contributing my part in my organisation's purpose'? As Blackman et al. (2013) observe, given the compelling mission underpinning public service work, there is growing acknowledgement that purpose is underleveraged as a medium for driving performance (see also MacLeod and Clarke 2011; Marrelli 2011). A clearly articulated purpose instils strategic clarity in a volatile, rapidly changing world. It serves as a 'North Star', a fixed point against which leaders, teams and individuals can align, and realign, their efforts to sustain effort in ambiguity and maintain focus on what matters in the face of multiple, competing demands. We cannot over-emphasise the difference between a discussion around task and one around purpose.

This approach is reflected in the recent changes by the State Services Commission (2015) which has channelled effort into redefining performance expectations of senior executives, moving towards a private sector model to achieve a 'step-up in performance and measurably better results for New Zealanders'. Efforts have also been focused on enhancing alignment between the government's priorities and the responsibilities of individual public servants, as well as translating outcomes into something meaningful for staff (Audit New Zealand 2012; Dormer and Gill 2010). Granted, the APS operates in an interdependent network of layers of government and so there is a complexity to be navigated here, but the complexity in turn demands clarity of purpose and a more interactive and networked way of setting priorities, goals and purpose in order to facilitate the alignment and accountability at all levels.

Further, research suggests a task-based approach results in employees closing down cognitively, emotionally and perceptually (Boyatzis, Rochford and Taylor 2015). Instead, when leaders facilitate dialogue around the organisation's purpose, it helps raise levels of commitment and personal investment because individuals sense that what they are doing is contributing to the achievement of a meaningful outcome larger than themselves (MacLeod and Clarke 2011; Terez 2003). Extending this dialogue about the organisation's purpose to enable individuals to identify, define and articulate their unique contribution improves engagement and creates meaning (Rose 2014). 
Despite the connection between purpose and performance, a large number of employees remain disengaged from their work. According to the Gallup Employee Engagement Index, only 13 percent of employees worldwide are engaged. In Australia, whilst 80 percent of public sector respondents 'believe strongly in the purpose of [their] agency', only 49 percent of respondents reported that their 'agency really inspires [them] to do [their] best work every day' (APSC 2019a). These findings suggest that, whilst a purposeful strategic narrative is essential, especially when facing complexity, it is also critical to engage individuals to shape their contribution to the outcomes and impacts in society.

Finally, in this approach, we believe that there is a strong need to have an explicit discussion about the types of capabilities required. The notion of 'dynamic capabilities' (those capabilities that support more adaptive cultures to emerge - for example, digital dexterity, adaptive leadership, collaboration, strategic thinking, creativity, problem definition, facilitation) for teams and individuals so they can adapt their skills and effort to contribute meaningfully over time is central to this suggestion. In practical terms, it requires facilitated consideration of questions such as 'What capabilities (beyond functional and technical capability) will we as a team need to deliver on our purpose?'

\section{MOTIVATE INDIVIDUALS AND GROUPS TO EXCEL, PERFORM AND DELIVER OUTCOMES}

The second key element of our proposed approach focuses on what is motivating and driving performance in the APS and on better aligning motivational efforts to factors that will increase and steer motivation towards the outcomes and standards we seek. Here we consider new methods for peer feedback, learning beyond classroom/formal training, opportunities for self-reflection and strengths-based approaches to work allocation.

Traditional public sector performance management systems tend to place emphasis on areas for improvement and development (Tombough 2005). This focus on improvement needs can, inadvertently, give the process a somewhat negative focus. Under this approach, managers identify employees' weaknesses or development requirements (e.g., deficiencies in their performance, behaviour, knowledge and skills), provide feedback on what the employee is doing right and wrong or what the employee did not accomplish, and ask them to improve their behaviours or results by addressing their development needs and overcoming their weaknesses (Aguinis, Gottfredson and Joo 2012). The underpinning assumption is that informing the individual of problems will motivate them to improve their performance.

Although feedback informs employees that certain behaviours and results are inappropriate or inadequate, several studies conclude that deficit-based models of performance management involve unintended negative consequences (Aguinis, Gottfredson and Joo 2012). For example, when negative feedback and criticism is conveyed it is often not seen as useful, is unlikely to be accepted as accurate or legitimate, causes defensive reactions, results in less acceptance of the feedback, decreases the recipient's desire and willingness to improve their performance or change their behaviour based on the feedback (Jawahar 2010; Steelman and Rutkowski 2004). This may explain why one extensive review of 131 studies found that, in more than one-third of cases, performance feedback actually resulted in decreased performance (Kluger and DeNisi 1996). Furthermore, it may also explain why the provision of feedback is frequently avoided altogether due to the inherent discomfort and lack of observable behaviour change. We argue 
that information about the extent to which individuals are meeting performance expectations is critical, but the openness of the recipient to acting on this information is impacted by the skills and focus of the person delivering the information.

One study compared performance reviews focused on an individual's weaknesses versus performance reviews focused on an individual's strengths, and found stark differences in the recipient's neurological reactions (Jack et al. 2013). Performance discussions focused on weaknesses in relation to targets or externally defined criteria resulted in avoidance behaviours, guilt and self-consciousness. In contrast, performance discussions focused on an individual's strengths and future aspirations activated neural regions that caused the recipient to be open and motivated to change. Our brains react fundamentally differently, depending on how performance information is framed. Furthermore, employee strengths are of great potential for growth, motivation and development. Highlighting how an individual's strengths can generate success in the workplace motivates employees to intensify the use of their strengths to produce even more positive performance, behaviours, and results (Buckingham and Clifton 2001).

In contrast to weakness-based feedback, strengths-based feedback enjoys a significant number of advantages with few, if any, negative consequences. For example, strengths-based feedback increases engagement and performance (Clifton and Harter 2003; Seligman et al. 2005), increases employees' desire to improve their productivity (Jawahar 2010) and heightens actual productivity (Clifton and Harter 2003). Additionally, the strengths-based approach to performance begs the question: why should performance appraisal be so uniform, incorporating identical processes for the entire organisation, with only minor adjustments for unique individuals in specific jobs? (Rabenu and Tziner 2016). In a world where so much has become customised to the individual - medical care adjusted to one's genetic profile, insurance policies determined by vehicle usage, music tailored to individuals during ride share journeys, and so on - support for performance could also be more personalised to maximise engagement and individual contributions.

Further, the proposed approach focuses on normalising learning as 'the one skill to rule them all' (Iliadis 2018), by, over time, normalising reflection and feedback. The adaptive, problem solving oriented public services we are trying to create require constant change and learning. It has been argued that 'the only way for organisations to ensure their workforces are fully productive and able to achieve business goals is to make sure employees are continuously learning, so that they are driving the [organisation] forward' (Wadors 2016). Beyond learning to evolve the organisation, the work of Dweck (2008) repeatedly highlights that cultivating a growth mindset may be a good way to increase employee engagement. We argue that, in order to create an environment for high performance amidst complexity, new approaches need to genuinely value ongoing learning and support the development of a culture that nurtures continual reflection, learning and growth where, from leaders to new recruits: we are all teachers and we are all students (Singler 2018).

Practically, this is likely to involve regular (perhaps monthly) facilitated discussions whereby the teams come together to reflect - as a team, and personally - on what they have learnt and will take forward in service of theirs and the organisational unit's purpose. These discussions need to be skilfully facilitated to achieve no-blame continuous reflection, learning, improvement and adjustment discussions to drive innovation. We acknowledge that shifting to this approach will take time, however we believe the focus on strengths, the alignment with purpose and the support of skilful facilitation will generate results. 
Ideally, over time, technology will enable ongoing, continual feedback from multiple sources and contact points that supports growth in real time via smart technology. This could include receiving ongoing feedback via technological platforms from those with whom the individual interacts in a fashion aimed at 'nudging' individual behaviours towards defined high performance standards (Ebert and Freibichler 2017; Singler 2018).

\section{THE ROLE OF PUBLIC SERVICE LEADERS IN GENERATING A HIGH-PERFORMANCE ENVIRONMENT}

The third key element in reinventing the approach to performance management to better serve the cultural shift public services are seeking to achieve, is redefining the traditional role and responsibilities allocated to the 'manager'. To support the role of leaders to facilitate high performance and shift the culture of the public service, it is clear that leaders need to shift from managing, reviewing and assessing performance on an annual basis in order to meet imposed deadlines, to a role as facilitator of the ongoing collaborative, diagnostic, learning processes outlined above.

From the inception of performance management practices, one key assumption has been universal: that a manager is best placed to decide on goals, review an employee's performance and identify and determine their development and improvement. Further, we propose that the focus that is created by performance management systems is that managers are expected to know what good and bad is in finite terms. Grote notes 'What a performance appraisal requires is for one person to stand in judgement of another. Deep down it's uncomfortable' (in Knight 2011). Blackman et al. (2015) report that while people in the public service can see the value in performance management, managers reported feeling 'abandoned' and 'unprepared' and that this led to a focus on compliance rather than using performance management for positive and performance enhancing purposes.

Further, much of the research calls out the dearth of managerial capability to actually manage performance let alone create a culture for high performance. This conclusion is supported by the findings in the Thodey Review which connect the failure of the current performance management systems with senior executives who do not prioritise employee performance and development because 'officers in senior roles have been promoted for their ability to deliver' (Department of the Prime Minister and Cabinet 2019, p. 207) rather than their role in leading and managing people. The review also notes that senior officers have been rewarded for their responsiveness, achieving 'results at all costs' and getting things 'right first time'. We contend that this is a factor contributing to the performance challenge - senior leaders in the public service prioritise this responsiveness over more strategic organisational thinking including investing effort in the development and engagement of their people. Their role as responders to the political arm and emergent policy imperatives may come at the cost of the strategic stewardship of the long-term sustainable performance of the service. Combine this with the hierarchical structures and cultural norms that still pervade, with 70 percent of employees still believing the APS is too hierarchical (APSC 2019a) and the promotion of people with primarily technical skills into leadership roles, and it is unsurprising that managers and leaders tend not to pay attention to long-term people and cultural development.

Our proposal is that we support leaders to take a different role in creating the environment for high performance. That we support leaders to take on the role of enabling and facilitating high 
performance, rather than being the judge, jury and executioner. We think it is more powerful to support leaders to impact performance by the way they engage people in purpose (Hamstra et al. 2014; Williams and Alshahrani 2017). All too often, people in leadership positions begin performance conversations by outlining tasks and metrics (e.g., what you need to do and how you will be measured). Performance management systems generally require managers and staff to define and outline tasks with a due date which, due to the pace of change, are often outdated or redundant by the time they are recorded in the HR system. This creates practice that focuses on form completion for the purposes of complying with a process that is driven by and perceived to be owned by human resources functions with efforts being channelled to chase and cajole those whose form remains incomplete at the arbitrarily determined due date.

Our assertion is that it is important to engage leaders to reconceptualise their role - as facilitators and enablers of high performance. They should not be expected to know everything, nor set everyone's goals and then somehow make effective judgements about whether they have achieved them. The leader role should be reconceptualised as being accountable for facilitating collaborative, diagnostic processes that are action- and outcomes-oriented, thereby leading to high performance. In this context, we propose the role of leaders is to steer and steward people to navigate the ambiguity inherent in complex situations, rather than providing answers or solutions based on expertise or superior positional authority. In this complex and dynamic environment, leaders can learn and coach their people to sense new challenges and changes in the business environment, and embrace innovation thereby creating the conditions by which people and organisations can become capable of continually adapting.

\section{THE ROLE OF THE HUMAN RESOURCES FUNCTION}

The role of human resources functions becomes vital in this new approach. It requires a shift in the role from being the compliance police towards becoming skilled coaches and facilitators of leaders and teams to create environments where high performance is the norm. Increasingly a core role of HR functions is to support the organisation to shape the purpose, settings and tools for performance practices and to shift further towards an outcomes-orientation rather than compliance with process.

It is widely recognised that human resources functions need to become a true business partner, supporting leaders and line managers in the delivery of high performance. KPMG's Future of HR 2019 survey, which gathered views from over 1,300 HR executives from across the globe, found that three in five human resources leaders believe that the HR function will rapidly become irrelevant if it does not modernise and adapt its approach to understanding and planning for the future needs of the workforce.

In practical terms, the HR function becomes a performance facilitator supporting leaders facilitating sessions that establish the conditions for achievement of organisational and individual outcomes. HR practitioners focus on coaching leaders in their role to facilitate purpose, roles and feedback discussions.

The human resources function also has the critical role of identifying and establishing workforce capability requirements and curating learning methods and equipping leaders to take on the roles of coach, mentor and feedback and debriefing provider. 


\section{SUMMARY AND AREAS FOR BROADER EXPLORATION}

In summary, we argue that there are four key ideas to work with to create high-performance environments in the public sector. As we have explored above, creating space for an interactive learning dialogue to define outcomes across boundaries and clarify the learning required to achieve the outcomes is key, and in doing so people find meaning and purpose in their work aligned to organisational purpose. Motivating individuals to excel through continuous learning and strengths-based engagement, and supporting both of these shifts by supporting leaders to reconceptualise their role in leading for high performance and changing the role that HR plays in facilitating high performance.

Beyond the research briefly mentioned in this chapter, there are a number of broader domains worthy of exploration to improve performance practices in the public sector. For example, immense insights can be drawn from different fields of research and practice including anthropology, behavioural economics, and neuropsychology, about how we can support humans to thrive. These sources need to be analysed, investigated, considered and incorporated into future approaches to maximise human capital in public sector organisations. Additionally, public sector organisations need to properly capture and exploit data to enable the targeting of organisational 'hotspots' where additional support is required to lift and sustain performance. Exploitation of available data enables the organisation to use foresight and insights to channel efforts into particular leaders, teams and projects to facilitate dialogue, provide coaching to enhance self-reflection and support learning and adjustments in practices and habits. Finally, given the reduction of barriers between home and work, performance needs to be considered more holistically. Workplace mental health claims are increasing exponentially, and there is an increasing requirement to focus on strategic recovery, resilience, and well-being to sustain performance over the longer-term. If this is ignored, superficial performance issues will escalate into complex, time-consuming cases, impacting on financial performance and absorbing large amounts of human resource effort.

\section{CONCLUSION}

Ever-changing citizen expectations and complex challenges require a markedly different public service; one that is citizen-oriented, innovative, agile and joined up. Performance management is a mechanism that, if fundamentally reoriented to this purpose, can support the shift of the public service to this new reality. The approach we have recommended for consideration is oriented to an integrated view of the performance of the system, organisation, group and individual, a focus on purpose, rather than task, owned by teams, not managers and explicit about the capabilities needed for success. Further, ongoing dialogue encourages strength-based mechanisms for learning with leaders operating as facilitators and enablers rather than determiners or judges of performance. Human resources functions play a very different role - coach and facilitator of performance and outcomes rather than guardians of a compliance-driven system focused on individual performance. It is our hope the ideas and thinking outlined here provide a framework for further consideration in both academic and practitioner circles. 


\section{REFERENCES}

Aguinis, H., R.K. Gottfredson and H. Joo (2012), 'Using performance management to win the talent war', Business Horizons, 55 (6), 609-616, https://doi.org/10.1016/j.bushor.2012.05.007.

Audit New Zealand (2012), Performance reporting, New Zealand Government, https://auditnz.govt.nz/ good-practice/performance/performance-management.

Australian Public Service Commission (APSC) (2019a), APS employee census 2019, Australian Government, https://www.apsc.gov.au/aps-employee-census-2019.

Australian Public Service Commission (APSC) (2019b), New directions on performance management, Commonwealth of Australia, https://www.apsc.gov.au/apsnews/new-directions-performance -management.

Baird, K., H. Schoch and Q.J. Chen (2012), 'Performance management system effectiveness in Australian local government', Pacific Accounting Review, 24 (2), 161-185. https://doi.org/10.1108/ 01140581211258461.

Blackman, D., F. Buick, M. O'Donnell, J. O'Flynn and D. West (2013), Strengthening the performance framework: Towards a high performing APS, Australian Government, https://www.apsc.gov.au/sites/ default/files/Performance accessible.pdf.

Blackman, D., D. West, J. O'Flynn, F. Buick and M. O’Donnell (2015), 'Performance management: Creating high performance, not high anxiety', in J. Wanna, H-A Lee and S. Yates (eds), Managing Under Austerity, Delivering Under Pressure: Performance and Productivity in Public Service, Australia: ANU Press, pp. 79-102.

Bommert, B. (2010), 'Collaborative innovation in the public sector', International Public Management Review, 11 (1), 15-33.

Boyatzis, R.E., K. Rochford and S.N. Taylor (2015), 'The role of the positive emotional attractor in vision and shared vision: Toward effective leadership, relationships, and engagement', Frontiers in Psychology, 6, 670 .

Buckingham, M. and D.O. Clifton (2001), Now, Discover your Strengths, New York: Simon \& Schuster.

Clifton, D.O. and J.K. Harter (2003), 'Investing in strengths', in K.S. Cameron, J.E. Dutton and R.E. Quinn (eds), Positive Organizational Scholarship: Foundations of a New Discipline, San Francisco: Berrett-Koehler Publishers, pp. 111-121.

Denhardt, R.B. and J.V. Denhardt (2000), 'The new public service: serving rather than steering', Public Administration Review, 60 (6), 549-559.

Denhardt, J.V. and R.B. Denhardt (2015), 'The new public service revisited', Public Administration Review, 75 (5), 664-672.

Department of the Prime Minister and Cabinet (2019), Our Public Service, Our future: Independent Review of the Australian Public Service, Commonwealth of Australia.

Dormer, R. and D. Gill (2010), 'Managing for performance in New Zealand's public service - a loosely coupled framework?', Measuring Business Excellence, 14 (1), 43-59, https://doi.org/10.1108/ 13683041011027445.

Drucker, P. (1954), 'Management by Objectives and Self-control, Practice of Management, New York: Harper \& Row.

Dweck, C.S. (2008), 'Brainology: Transforming students' motivation to learn', https://www.mccd.edu/ academics/english-liberalstudies/downloads/Brainology_85E.pdf.

Ebert, P. and W. Freibichler (2017), 'Nudge management: Applying behavioural science to increase knowledge worker productivity', Journal of Organization Design, 6 (1), 1-6.

Fatile, J.O. (2014), 'Performance management systems productivity in the public sector: Wither African public administration', Africa's Public Service Delivery and Performance Review, 2 (3), 77-105.

Goler, L., J. Gale and A. Grant (2016), 'Let's not kill performance evaluations yet', Harvard. Business Review, https://hbr.org/2016/11/lets-not-kill-performance-evaluations-yet.

Gray, B. (2008), 'Enhancing transdisciplinary research through collaborative leadership', American Journal of Preventive Medicine, 35 (2), S124-S132.

Hamstra, M.R., K. Sassenberg, N.W. Van Yperen and B. Wisse (2014), 'Followers feel valued: When leaders' regulatory focus makes leaders exhibit behavior that fits followers' regulatory focus', Journal of Experimental Social Psychology, 51, 34-40. 
Huxham, C. and S. Vangen (2013), Managing to Collaborate: The Theory and Practice of Collaborative Advantage, London: Routledge.

Iliadis, N. (2018), 'Learning to learn - the future proof skill', Big Innovation Centre, http://www.appg-ai .org/wp-content/uploads/2018/10/learning-to-learn_final_report_bic_kpmg.pdf.

Institute for Government (2019), Lessons for Civil Service Reform: shape the future, Institute for Government, https:/www.instituteforgovernment.org.uk/our-work/ whitehall/lessons-civil-service-reform.

Jack, A.I., R.E. Boyatzis, M.S. Khawaja, A.M. Passarelli and R.L. Leckie (2013), 'Visioning in the brain: An fMRI study of inspirational coaching and mentoring', Social Neuroscience, 8 (4), 369-384.

Jawahar, I.M. (2010), 'The mediating role of appraisal feedback reactions on the relationship between rater feedback-related behaviors and ratee performance', Group and Organization Management, 35 (4), 494-526.

Kluger, A. and A. DeNisi (1996), 'The effects of feedback interventions on performance: A historical review, a meta-analysis, and a preliminary feedback intervention theory', Psychological Bulletin, 119, 254-284.

Knight, R (2011), 'Delivering an effective performance review', Harvard Business Review, https://hbr .org/2011/11/delivering-an-effective-perfor.

Kourtit, K. and A.A. de Waal (2008), 'Strategic performance management in practice: Advantages, disadvantages and reasons for use', http://citeseerx.ist.psu.edu/viewdoc/download?doi=10.1.1.835 $.4430 \&$ rep $=$ rep $1 \&$ type $=$ pdf.

KPMG (2019), 'The future of HR: Which path are you taking', https://home.kpmg/xx/en/home/insights/ 2019/11/the-future-of-human-resources-2020.html.

Lawler, E.J. (2003), 'Reward practices and performance management system effectiveness', Organizational Dynamics, 32 (4), 396-404, doi: 10.1016/j.orgdyn.2003.08.007.

Maccoby, M. (2007), The Leaders We Need: And What Makes Us Follow, Brighton, MA: Harvard Business Press.

Maccoby, M. (published online 2016), 'The human side: How to be a quality leader', Research Technology Management, 33 (5), 51-52, doi: 10.1080/08956308.1990.11670689.

MacLeod, D. and N. Clarke (2011), 'Engaging for success: Enhancing performance through employee engagement, a report to government', https://www.gov.uk/government/speeches/civil-service -transformation-speech.

Manzoni, J. (2018), Civic Service Transformation speech, http://www.gov.uk/government/speeches/ civil-service-transformation-speech.

Marrelli, A.F. (2011), 'Employee engagement and performance management in the federal sector', Performance Improvement, 50 (5), 5-13.

Metawie, M. and M. Gilman (2005), 'Problems with the implementation of performance measurement systems in the public sector where performance is linked to pay: A literature review drawn from the UK', presented at 3rd Conference on Performance Measurements and Management Control, 22-23 September, Nice, http://citeseerx.ist.psu.edu/viewdoc/download?doi=10.1.1.104.9267\&rep=rep1\& type $=$ pdf.

Neely, A.D. (1998), Measuring Business Performance, London: Profile Books.

NSW Public Service Commission (2019), 'Strategic directions towards 2025', https://www.psc.nsw.gov .au/about-us/strategic-directions-towards-2025.

Public Sector Commission (2013), 'Performance management in the public sector, a review of how agencies conduct performance management', Government of West Australia, https://publicsector.wa.gov .au/document/performance-management-public-sector-review-how-agencies-conduct-performance -management.

Rabenu, E. and A. Tziner (2016), 'Performance appraisal in a constantly changing work world', Industrial and Organizational Psychology, 9 (2), 370-377.

Rose, M. (2014), The Mind at Work: Valuing the Intelligence of the American Worker, London: Penguin Books.

Seligman, M.E.P., T.A. Steen, N. Park and C. Peterson (2005), 'Positive psychology progress: Empirical validation of interventions', American Psychologist, 60 (5), 410-421. https://doi.org/10.1037/0003 -066 X.60.5.410. 
Singler, E. (2018), Nudge Management: Applying Behavioural Science to Boost Well-Being, Engagement and Performance at Work, London: Pearson.

State Services Commission (2015), 'Approach to public service executive management', New Zealand Government, https://ssc.govt.nz/resources/approach-statesector-executive-management?e908=action viewall.

State Services Commission (2019), 'Impact statement: State sector reform act', New Zealand Government, https://ssc.govt.nz/assets/Legacy/resources/Impact-Statement-State-Sector-Act-Reform.pdf.

Steelman, L.A. and K.A. Rutkowski (2004), 'Moderators of employee reactions to negative feedback', Journal of Managerial Psychology, 19 (1), 6-18, https://doi.org/10.1108/02683940410520637.

Terez, T. (2003), ‘A burning sense of mission', Workforce, 82 (4), 26. https://login.wwwproxy1.library .unsw.edu.au/login?qurl=https\%3A\%2F\%2Fwww.proquest.com\%2Ftrade-journals\%2Fburning -sense-mission\%2Fdocview\%2F219798140\%2Fse-2\%3Faccountid\%3D12763.

Thodey, D. (2019), 'IPAA address: Priorities for change', Australian Public Service Commission, https:// www.apsreview.gov.au/news/ipaa-address-priorities-change.

Tombaugh, J.R. (2005), 'Positive leadership yields performance and profitability: Effective organizations develop their strengths', Development and Learning in Organizations: An International Journal, 19 (3), 15-17.

Torfing, J. (2019), 'Collaborative innovation in the public sector: The argument', Public Management Review, 21 (1), 1-11.

Uhl-Bien, M. and M. Arena (2017), 'Complexity leadership: Enabling people and organizations for adaptability, Organizational Dynamics, 46 (1), 9-20.

UK Government (2009), 'UK Commission for Employment and Skills annual report 2009 to 2010', UK Government, https://www.gov.uk/government/publications/uk-commission-for-employment-and -skills-annual-report-2009-to-2010.

Wadors, P. (2016), 'To stay relevant, your company and employees must keep learning', Harvard Business Review, https://hbr.org/2016/03/to-stay-relevant-your-company-and-employees-must-keep -learning.

Wernerfelt, B. (1984), 'A resource-based view of the firm', Strategic Management Journal, 5 (2), $171-180$.

Williams, C.H. and S. Alshahrani (2017), 'Organisational commitment and transformational leadership in different contexts: Strong and complex relationship as reflected in the literature', International Journal of Business and Management Studies, 6 (1), 295-314.

World Economic Forum (2016), 'Ten skills you need to thrive in the fourth industrial revolution', World Economic Forum, https://www.weforum.org/agenda/2016/01/the-10-skills-you-need-to-thrive-in-the -fourth-industrial-revolution/.

World Economic Forum (2018), 'The response to a question to the business leaders surveyed in the Future of Jobs survey asking the share of core skills of jobs within their enterprise that will stay constant between today and 2022', World Economic Forum, http://www3.weforum.org/docs/WEF Future_of_Jobs_2018.pdf.

World Economic Forum (2019), 'Strategies for the new economy: Skills as the currency of the labour market', World Economic Forum, https://www.weforum.org/whitepapers/strategies-for-the-new -economy-skills-as-the-currency-of-the-labour-market.

Yon Ying-I (2019), Permanent Secretary of the Public Service Division, Prime Minister's Office, Singapore, quoted in Ross, M., Enter the Era of Enterprise: Leadership in the 2020s, https://www.g lobalgovernmentforum.com/entering-an-era-of-enterprise-leadership-in-the-2020s/. 